\title{
François Béroalde de Verville, Le Moyen de parvenir, tome I Transcription, tome II Fac simile
}

\section{Monica Pavesio}

\section{(2) OpenEdition}

\section{Journals}

\section{Edizione digitale}

URL: http://journals.openedition.org/studifrancesi/27512

DOI: 10.4000/studifrancesi.27512

ISSN: 2421-5856

Editore

Rosenberg \& Sellier

\section{Edizione cartacea}

Data di pubblicazione: 31 décembre 2006

Paginazione: 597

ISSN: 0039-2944

\section{Notizia bibliografica digitale}

Monica Pavesio, « François Béroalde de Verville, Le Moyen de parvenir, tome I Transcription, tome II Fac simile », Studi Francesi [Online], 150 (L | III) | 2006, online dal 30 novembre 2015, consultato il 08 novembre 2020. URL : http://journals.openedition.org/studifrancesi/27512 ; DOI : https://doi.org/ 10.4000/studifrancesi.27512

Questo documento è stato generato automaticamente il 8 novembre 2020

\section{(c) $(1)$}

Studi Francesi è distribuita con Licenza Creative Commons Attribuzione - Non commerciale - Non opere derivate 4.0 Internazionale. 


\title{
François Béroalde de Verville, Le Moyen de parvenir, tome I Transcription, tome II Fac simile
}

\author{
Monica Pavesio
}

\section{NOTIZIA}

FRANÇOIS BÉROALDE DE VERVILLE, Le Moyen de parvenir, tome I Transcription avec présentation, notes et index par H. MOREAU et A. TOURNON, avec la collaboration de J. L. RISTORI, Paris, Champion, 2004, pp. 496; tome II Fac simile édité par H. MOREAU et A. TOURNON avec la collaboration de J. L. RISTORI, Présentation d'A. Tournon, Paris, Champion, 2004, pp. 322.

1 «Oeuvre contenant la raison de tout ce qui a été, est et sera; avec démonstrations certaines et nécessaires, selon la rencontre des effets de Vertu»: così François Béroalde de Verville presenta il suo libro Le Moyen de parvenir, ripubblicato da H. Moreau e A. Tournon, vent'anni dopo la prima edizione da loro stessi curata.

2 Un breve hors texte iniziale serve da presentazione a questa singolare opera di Verville, pubblicata anonima ed attribuita al figlio del teologo calvinista Beroaldus solo in epoca moderna. Si tratta, come è risaputo, di un flusso verbale sconcertante in cui riso, filosofia e delirio si fondono a meraviglia; un'opera originale e scandalosa che i curatori ripropongono con ortografia modernizzata e con un ricco apparato di note esplicative, varianti delle differenti edizioni ed approfondite note intertestuali con riferimenti alle altre opere di Verville, curate da J. L. Ristori.

3 Una breve biografia di Verville, una bibliografia degli studi fondamentali dedicati al Moyen de parvenir, un repertorio tematico, un indice dei nomi ed un repertorio alfabetico dei titoli e delle numerose sezioni in cui Verville suddivide il suo trattato completano il primo tomo. 
4 Nel secondo volume i curatori riproducono il facsimile dell'edizione del libro di Verville in 617 pagine, pubblicata in forma anonima senza luogo né data. Anche in questo caso, si tratta di una seconda pubblicazione dopo quella del 1984, ormai introvabile, edita dal Servizio di pubblicazione dell'Università di Provenza e destinata agli specialisti ed agli studiosi di questo originale scrittore a cavallo fra il cinquecento ed il Seicento. 